\title{
Corneal Hydrops in Keratoconus
}

\author{
${ }^{1}$ Prafulla K Maharana, ${ }^{2}$ Ritu Nagpal, ${ }^{3}$ Namrata Sharma
}

\section{ABSTRACT}

Purpose: The purpose of this review is to outline the etiology, clinical features, and management of acute corneal hydrops $(\mathrm{CH})$ in cases of keratoconus $(\mathrm{KC})$.

Recent findings: The advent of newer investigative modalities like ultra biomicroscopy, anterior segment optical coherence tomography and confocal microscopy has contributed toward the diagnosis, treatment planning and following the course of therapy in cases of acute hydrops.

Summary: Corneal hydrops is an acute complication of keratoconus which in most instances resolves spontaneously. However, prolonged corneal edema can lead to complications, such as corneal neovascularization which can jeopardise a future corneal graft. Hence, timely intervention is required in most cases to prevent such complications as well as for early visual rehabilitation. Intracameral gas injection is the most commonly performed surgical procedure for hydrops. Modifications in surgical technique can help to tackle difficult situations.

Keywords: Acute corneal hydrops, Corneal edema, Intracameral gas injection, Keratoconus.

How to cite this article: Maharana PK, Nagpal R, Sharma N. Corneal Hydrops in Keratoconus. Int $\mathrm{J}$ Kerat Ect Cor Dis 2015;4(2):52-55.

\section{Source of support: Nil}

Conflict of interest: None

\section{INTRODUCTION}

Acute corneal hydrops $(\mathrm{CH})$ is the development of marked corneal edema caused by a break in the descemet membrane (DM) allowing aqueous to leak into the stroma and epithelium. ${ }^{1-4}$ It is most commonly seen in cases of keratoconus $(\mathrm{KC})$, but has also been reported as a complication of other corneal ectasias like pellucid

\footnotetext{
${ }^{1}$ Assistant Professor, ${ }^{2}$ Senior Resident, ${ }^{3}$ Professor

${ }^{1}$ Department of Ophthalmology, All India Institute of Medical Sciences, Bhopal, Madhya Pradesh, India

${ }^{2}$ Department of Ophthalmology, All India Institute of Medical Sciences, Rishikesh, Uttarakhand, India

${ }^{3}$ Department of Cornea and Refractive Surgery, Dr Rajendra Prasad Centre for Ophthalmic Sciences, All India Institute of Medical Sciences, New Delhi, India

Corresponding Author: Prafulla K Maharana, Assistant Professor, Department of Ophthalmology, All India Institute of Medical Sciences, Bhopal, Madhya Pradesh, India, Phone: +918818984280, e-mail: prafulla.opth@aiimsbhopal.edu.in
}

marginal corneal degeneration (PMCD), keratoglobus and Terrien's marginal degeneration (TMD). ${ }^{1}$ The reported incidence ranges from 2.6 to $35 \%{ }^{2}$

\section{Epidemiology and Risk Factors}

Risk factors for $\mathrm{CH}$ include young age, male sex, poor visual acuity at presentation, steep keratometry, ${ }^{2}$ severe ectasia at presentation, ${ }^{5}$ eccentric cone location, ${ }^{6}$ co-existent vernal keratoconjunctivitis, ${ }^{7}$ down syndrome, ${ }^{8}$ congenital rubella, ${ }^{9}$ corneal microtrauma due to repeated eye rubbing. Among all associated factors eye rubbing is the most important risk factor. ${ }^{3}$

\section{Natural History of Corneal Hydrops}

Acute hydrops develops when the DM of ectatic cornea splits, allowing the aqueous to seep into the stroma. Often a preceding history of vigorous eye rubbing or coughing is present. ${ }^{10}$ The elasticity of DM causes its edges to retract and curl anteriorly, ${ }_{11}$ and this is responsible for the delayed resolution of corneal edema associated with hydrops compared to that developing after a DM breach developing during cataract surgery on a keratoconic eye. ${ }^{12}$

Continuous seepage of aqueous separates the collagen lamellae and forms large fluid-filled stromal pockets and epithelial bullae. ${ }^{13}$ Subsequently, over a period of time ranging from 2 to 4 months, the adjacent endothelial cells enlarge and migrate to cover the defect as a part of reparative process. This seals the defect and prevents further seepage of aqueous leading to resolution of hydrops. ${ }^{14,15}$

\section{Clinical Features}

The onset of acute hydrops is usually heralded by sudden onset of watering, photophobia, pain and markedly reduced visual acuity. ${ }^{2}$ Slit-lamp examination reveals conjunctival hyperemia, epithelial microcystic edema, and marked stromal edema with intervening fluid clefts. Corneal edema can be graded depending upon its extent of involvement with grade 1 as stromal edema limited to a circle of $3 \mathrm{~mm}$ diameter, grade 2 as edema between circles of 3 and $5 \mathrm{~mm}$ diameters, and grade 3 as edema extending beyond a circle of $5 \mathrm{~mm}$ diameter. ${ }^{13}$

Although most cases resolve with a scar, complications can occur, such as corneal neovascularization, ${ }^{2,16}$ keratitis, pseudo cyst formation, and corneal perforation. ${ }^{2,3}$ 


\section{Investigations}

Investigations help to determine the size and extent of stromal edema and to localize the DM tear which helps to plan the treatment, monitor the esponse of therapy, and identify any complication developing during follow-up. These include ultrasound biomicroscopy (UBM), anterior segment optical coherence tomography (ASOCT) and confocal microscopy.

\section{Ultrasound Biomicroscopy}

In acute phase UBM clearly delineates DM tear as an area of deficiency under the site of maximum corneal edema. ${ }^{12,13}$ The characteristic continuous curvilinear and brightly intense spike of an intact DM is absent. It reveals the number (single or multiple), site, size, and communication of intrastromal cysts/clefts and the length of tear.

\section{Anterior Segment Optical Coherence Tomography}

Anterior segment optical coherence tomography reveals epithelial and stromal edema, intrastromal fluid clefts and DM detachment. Intrastromal cysts appear as hyporeflective areas within the stromal bed. ${ }^{17}$ It helps to document serial corneal thickness measurements and, thereby aids in monitoring the response of treatment. ${ }^{18-20}$ Three patterns of DM appearance have been described during acute hydrops: detachment with break and rolled ends, detachment with break and flat ends, and detachments with no break. ${ }^{19}$

\section{Confocal Microscopy ${ }^{21}$}

Confocal microscopy helps to demonstrate epithelial as well as stromal edema. It reveals epithelial wing cells as hyper-reflective areas suggestive of fluid influx. The keratocyte densities are lower in the edematous area and have oddly shaped nuclei. ${ }^{21}$

\section{Management}

Most cases of $\mathrm{CH}$ resolve spontaneously without intervention over a period of 2 to 4 months. However, increasing duration of corneal edema predisposes to an increased risk of corneal complications, such as neovascularisation, therefore, many therapeutic options employed today aim to facilitate early resolution of hydrops. Treatment regimens can be divided into conservative and surgical options.

\section{Conservative Treatment}

Medical therapy primarily aims to provide symptomatic relief till spontaneous resolution occurs. It usually includes topical lubricants, broad spectrum topical anti- biotics (to prevent secondary infection), cycloplegics (to reduce pain and photophobia), hyperosmotic agents (to reduce epithelial and intrastromal edema), anti-glaucoma medications (to lessen the hydrodynamic force on posterior corneal surface), and topical steroids or nonsteroidal anti-inflammatory drugs (to reduce inflammation and prevent neovascularization). ${ }^{1-3,22}$ Topical NSAIDs should be used cautiously as they may lead to stromal thinning or corneal perforation when used at higher doses (>7 drops per day). ${ }^{23,24}$

\section{Surgical Therapy}

Various surgical modalities employed for $\mathrm{CH}$ management are as follows:

- Intracameral air/gas injection

Various agents, which have been tried for intra cameral injection include air, ${ }^{25} 20 \%$ sulfur hexafluoride $\left(\mathrm{SF}_{6}\right)^{26}$ and $14 \%$ perfluoropropane $\left(\mathrm{C}_{3} \mathrm{~F}_{8}\right){ }^{13,23}$ The difference among these agents, is the duration of action. Air is the shortest acting agent hence repeated injections are required. ${ }^{25}$ Sulfur hexafluoride is longer acting compared to air (stays for around 2 weeks) however, repeat injections may still be required. ${ }^{26}$ Perfluoropropane is the longest acting agent and usually repeat injections are not needed. ${ }^{23}$

Intracameral air/gas injection acts by following mechanisms; reposits DM to the corneal stroma by bringing its ends close together, acts as a mechanical barrier against further fluid entry ${ }^{25,26}$ and facilitates faster healing of endothelial cells over the exposed stroma. ${ }^{25,26}$

\section{Surgical Technique}

Preoperative pupillary constriction is achieved using topical $2 \%$ pilocarpine nitrate to avoid intraoperative injury to the lens. $0.1 \mathrm{ml}$ aqueous humor is aspirated using a 26/27 gauge needle followed by of air/gas injection (20\% nonexpansile concentration of $\mathrm{SF}_{6}$ or $14 \%$ nonexpansile concentration of $\mathrm{C}_{3} \mathrm{~F}_{8}$ ) so as to fill two-third anterior chamber. ${ }^{25,26}$ An alternate technique involves inserting a second empty tuberculin syringe with a $26 / 27$ gauge needle without plunger in an oblique fashion into the anterior chamber from a different site so that the aqueous humor is pushed out through the second syringe when gas in the first tuberculin syringe is injected into the anterior chamber. ${ }^{13}$ The latter technique allows smooth unrolling of the curled descemet membrane. A surgical peripheral iridectomy may be performed before injection to avoid papillary block glaucoma. ${ }^{22}$

Postoperatively, supine position is advised for 2 weeks along with topical antibiotics, hypertonic saline, steroids and antiglaucoma medications. Repeat injections may be needed in cases with persistent corneal edema. ${ }^{25,26}$ The 
Table 1: Outcomes of commonly used procedures for acute hydrops management

\begin{tabular}{|c|c|c|c|c|c|c|}
\hline SI. no. & Author/years & Type of study & Intervention & Time for resolution & Repeat injections & Complication \\
\hline 1. & Miyata K et al $2002^{25}$ & $\mathrm{R}$ & Intracameral air & $\begin{array}{l}\text { Cases: } 20.1 \pm 9.0 \text { days } \\
\text { Controls: } 64.7 \pm 34.6 \text { days } \\
(p=0.0008)\end{array}$ & Required & None \\
\hline 2. & Panda A et al $2007^{26}$ & $P$ & $20 \% \mathrm{SF}_{6}$ & $\begin{array}{l}\text { Cases: } 4 \text { weeks } \\
\text { Controls: } 12 \text { weeks }\end{array}$ & Required & None \\
\hline 3. & Rajaraman R et al $2009^{31}$ & $\mathrm{R}$ & $\begin{array}{l}14 \% \mathrm{C}_{3} \mathrm{~F}_{8} \text { with } \\
\text { compression } \\
\text { sutures }\end{array}$ & $8.87 \pm 4.98$ days & Not required & None \\
\hline 4. & Basu S et al $2011^{22}$ & $\mathrm{R}$ & $14 \% \mathrm{C}_{3} \mathrm{~F}_{8}$ & $\begin{array}{l}\text { Cases: } 78.7 \pm 53.2 \text { days } \\
\text { Controls: } 117.9 \pm 68.2 \text { days } \\
(p=0.0001)\end{array}$ & Not required & $\begin{array}{l}\text { Pupillary block } \\
\text { glaucoma } \\
\text { (16\% cases) }\end{array}$ \\
\hline 5. & Sharma $\mathrm{N}$ et al $2011^{13}$ & $P$ & $14 \% \mathrm{C}_{3} \mathrm{~F}_{8}$ & $72-120$ days & Not mentioned & $\begin{array}{l}\text { Pupillary block } \\
\text { glaucoma and } \\
\text { intrastromal gas } \\
\text { migration }\end{array}$ \\
\hline 6. & Ting DS et al $2014^{35}$ & $\mathrm{R}$ & $14 \% \mathrm{C}_{2} \mathrm{~F}_{6}$ & $60.0 \pm 32.1$ days & Not required & None \\
\hline
\end{tabular}

R: Retrospective study; P: Prospective study

time of resolution of hydrops following intracameral air/gas injection has been found to be less in various studies $^{22,25}$ although the visual outcome may 26 or may not $^{22,25}$ improve (Table 1).

\section{Complications}

The complications of intracameral air/gas injection include intrastromal gas migration, ${ }^{27}$ pupillary block glaucoma, ${ }^{22}$ endothelial cell loss, ${ }^{28}$ cataract formation, keratitis ${ }^{25}$ and Urrets Zavalia syndrome. ${ }^{29}$ Intrastromal migration of the gas occurs due to fish egging of gas during the injection procedure, which prevents the closure of the intrastromal cleft and impedes the resolution of hydrops. $^{13,27}$

- Compressive sutures with gas injection

Application of compressive sutures along with gas injection has been reported to be successful in severe cases with wide separation of edges of descemet membrane and formation of cleft like structures with fistulous communication. Intracameral gases alone may fail to occlude the tear in these cases. Also trapping of gas in the stromal clefts can occur which can delay the resolution of edema ${ }^{27}$ and incite inflammation and vascularisation. ${ }^{30,31}$ Sutures bring the gaped edges close together and fasten the resolution of edema. Two to five full-thickness sutures with 10-0 nylon are applied across the tear, starting 1 to $2 \mathrm{~mm}$ from its edges after injecting the gas. The sutures are removed 2 to 6 weeks later. ${ }^{31}$

- Tissue adhesives with bandage contact lens (BCL)

Rarely in cases of severe acute hydrops a fistula may form. Cyanoacrylate tissue adhesive with BCL (TABCL) may succeed in sealing these small perforations, thereby avoiding emergency tectonic keratoplasty. ${ }^{32}$

- Amniotic membrane transplantation (AMT) with cauterization.
In cases with persistent corneal edema, 15 to 32 cautery applications under saline irrigation followed by stromal puncture with a 24-gauge disposable needle at the site of maximal edema and AMT has been reported. ${ }^{32}$ Cauterization allows excess water to evaporate from the stroma and AMT helps in reducing inflammation, vascularisation and scarring.

- Keratoplasty

Penetrating keratoplasty is rarely required in cases of acute corneal hydrops. Indications incude persistent corneal edema, ${ }^{3}$ corneal perforation, ${ }^{33}$ large DM tear, ${ }^{13,27}$ intrastromal cyst formation, ${ }^{27}$ and corneal neovascularisation. ${ }^{29}$

Deep anterior lamellar keratoplasty (DALK) offers less risk of endothelial graft rejection and better longterm graft survival compared to PK, however, it is more technically challenging.

Recently, use of descemet stripping endothelial keratoplasty (DSEK) has been reported in cases of hydrops with keratoglobus and chronic hydrops. However, the same has not been reported in cases of keratoconus. ${ }^{34}$

\section{CONCLUSION}

Acute corneal hydrops may be managed either with medical therapy alone or with surgical intervention. The use of intracameral gases may or may not improve the final BCVA, however, it does reduce the duration of corneal edema, thereby limiting the complications associated with long standing corneal edema like corneal neovascularisation which poses an increased risk of graft rejection and failure should a keratoplasty is performed later. Other treatment modalities, such as compressive sutures, tissue adhesives with bandage contact lens and amniotic membrane transplantation with cryotherapy may be helpful in special situations. 


\section{REFERENCES}

1. Sharma N, Maharana PK, Jhanji V, Vajpayee RB. Management of acute corneal hydrops in ectatic corneal disorders. Curr Opin Ophthalmol 2012 Aug;23(8):317-323.

2. Tuft SJ, Gregory WM, Buckley RJ. Acute corneal hydrops in keratoconus. Ophthalmology 1994 Oct;101(10):1738-1744.

3. Grewal S, Laibson PR, Cohen EJ, Rapuano CJ. Acute hydrops in the corneal ectasias: associated factors and outcomes. Trans Am Ophthalmol Soc 1999;97:187-203.

4. Sridhar MS, Mahesh S, Bansal AK, Nutheti R, Rao GN. Pellucid marginal corneal degeneration. Ophthalmology 2004 Dec;111(6):1102-1107.

5. Tuft SJ, Moodaley LC, Gregory WM, Davison CR, Buckley RJ. Prognostic factors for the progression of keratoconus. Ophthalmology 1994 Mar;101(3):439-447.

6. Perry HD, Buxton IN, Fine BS. Round and oval cones in keratoconus. Ophthalmology 1980 Sep;87(9):905-909.

7. Khan MD, Kundi N, Saeed N, Gulab A, Nazeer AF. Incidence of keratoconus in spring catarrh. Br J Ophthalmol 1988 Jan;72(1):41-43.

8. Cullen JF, Butler HG. Mongolism (Down's syndrome) and keratoconus. Br J Ophthalmol 1963 Jun;47(6):321-330.

9. Boger WP, Petersen RA, Robb RM. Keratoconus and acute hydrops in mentally retarded patients with congenital rubella syndrome. Am J Ophthalmol 1981 Feb;91(2):231-233.

10. Sharma R, Titiyal JS, Prakash G, Sharma N, Tandon R, Vajpayee RB. Clinical profile and risk factors for keratoplasty and development of hydrops in north Indian patients with keratoconus. Cornea 2009 May;28(4):367-370.

11. Stone DL, Kenyon KR, Stark WJ. Ultrastructure of keratoconus with healed hydrops. Am J Ophthalmol 1976 Sep;82(3): 450-458.

12. Nakagawa T, Maeda N, Okazaki N, Hori Y, Nishida K, Tano Y. Ultrasound biomicroscopic examination of acute hydrops in patients with keratoconus. Am J Ophthalmol 2006 Jun;141(6):1134-1136.

13. Sharma N, Mannan R, Jhanji V, et al. Ultrasound biomicroscopy-guided assessment of acute corneal hydrops. Ophthalmology 2011 Nov;118(11):2166-2171.

14. Wolter JR, Henderson JW, Clahassey EG. Ruptures of Descemet's membrane in keratoconus: causing acute hydrops and posterior keratoconus. Am J Ophthalmol 1967 Jun; 63(6):1689-1692.

15. Cameron JA, Al-Rajhi AA, Badr IA. Corneal ectasia in vernal keratoconjunctivitis. Ophthalmology 1989 Nov;96(11): 1615-1623.

16. Al Suhaibani AH, Al-Rajhi AA, Al-Motowa S, Wagoner MD. Inverse relationship between age and severity and sequelae of acute corneal hydrops associated with keratoconus. Br J Ophthalmol 2007 Jul;91(7):984-985.

17. Aurich H, Pham DT, Wirbelauer C. Biometric evaluation of keratoconic eyes with slit lamp-adapted optical coherence tomography. Cornea 2011 Jan;30(1):56-59.

18. Vanathi M, Behera G, Vengayil S, Panda A, Khokhar S. Intracameral $\mathrm{SF}_{6}$ injection and anterior segment OCT-based documentation for acute hydrops management in pellucid marginal corneal degeneration. Cont Lens Anterior Eye 2008 Jun;31(3):164-166.

19. Basu S, Vaddavalli PK, Vemuganti GK, Hasnat Ali Md, Murthy SI. Less. Anterior segment optical coherence tomography features of acute corneal hydrops. Cornea 2012 May;31(5): 479-485.

20. Kucumen BR, Yenerel NM, Gorgun E, Dinc UA. Anterior segment optical coherence tomography findings of acute hydrops in a patient with keratoconus. Ophthalmic Surg Lasers Imaging 2010 Nov-Dec;41 (Suppl):S114-116.

21. Thota S, Miller WL, Bergmanson JP. Acute corneal hydrops: a case report including confocal and histopathological considerations. Cont Lens Anterior Eye 2006 May;29(2):69-73.

22. Basu S, Vaddavalli PK, Ramappa M, Shah S, Murthy SI, Sangwan VS. Intracameral perfluoropropane gas in the treatment of acute corneal hydrops. Ophthalmology 2011 May;118(5):934-939.

23. Donnefeld ED, Schrier A, Perry HD, et al. Infectious keratitis with corneal perforation associated with corneal hydrops and contact lens wear in keratoconus. Br J Ophthalmol 1996 May;80(5):409-412.

24. Congdon NG, Schein OD, von Kulajta P, Lubomski LH, Gilbert D, Katz J. Corneal complications associated with topical ophthalmic use of nonsteroidal anti-inflammatory drugs. J Cataract Refract Surg 2001 Apr;27(4):622-631.

25. Miyata K, Tsuji H, Tanabe T, Mimura Y, Amano S, Oshikaet T. Intracameral air injection for acute hydrops in keratoconus. Am J Ophthalmol 2002 Jun;133(6):750-752.

26. Panda A, Aggarwal A, Madhavi P, et al. Management of acute corneal hydrops secondary to keratoconus with intracameral injection of sulfur hexafluoride $\left(\mathrm{SF}_{6}\right)$. Cornea 2007 Oct; 26(9): 1067-1069.

27. Sharma N, Mannan R, Titiyal JS. Nonresolution of acute hydrops because of intrastromal migration of perfluoropropane gas. Cornea 2010 Aug;29(8):944-946.

28. Green K, Cheeks L, Stewart DA, Norman BC. Intraocular gas effects on corneal endothelial permeability. Lens Eye Toxic Res 1992;9(2):85-91.

29. Aralikatti AKV, Tomlins PJ, Shah S. Urrets-Zavalia syndrome following intracameral $\mathrm{C}_{3} \mathrm{~F}_{8}$ injection for acute corneal hydrops. Clin Experiment Ophthalmol 2008 Mar;36(2): 198-199.

30. Rowson NJ, Dart JK, Buckley RJ. Corneal neovascularisation in acute hydrops. Eye 1992;6(Pt 4):404-406.

31. Rajaraman R, Singh S, Raghavan A, Karkhanis A. Efficacy and safety of intracameral perfluoropropane $\left(\mathrm{C}_{3} \mathrm{~F}_{8}\right)$ tamponade and compression sutures for the management of acute corneal hydrops. Cornea 2009 Apr;28(3):317-320.

32. Wylegala E, Tarnawska D. Amniotic membranetransplantation with cauterization for keratoconus complicated by persistent hydrops in mentally retarded patients. Ophthalmology 2006 Apr;113(4):561-564.

33. Aldave AJ, Mabon M, Hollander DA, McLeod SD, SpencerWH, Abbott RL. Spontaneous corneal hydrops and perforation in keratoconus and pellucid marginal degeneration. Cornea 2003 Mar;22(2):169-174.

34. Kolomeyer AM, Chu DS. Descemet stripping endothelial keratoplasty in a patient with keratoglobus and chronic hydrops secondary to a spontaneous descemet membrane tear. Case Reports in Ophthalmological Medicine, vol. 2013, Article ID 697403, 5 pages, 2013.

35. Ting DS, Srinivasan S. Pneumodescemetopexy with perfluoroethane $\left(\mathrm{C}_{2} \mathrm{~F}_{6}\right)$ for the treatment of acute hydrops secondary to keratoconus. Eye (Lond) 2014 Jul;28(7):847-851. 